\title{
Application of innovative smart wearable device in industry 4.0
}

\author{
Marko Periša ${ }^{1}$, Rosana Elizabeta Sente ${ }^{2}$, Ivan Cvitić ${ }^{3}$, Peter Kolarovszki ${ }^{4}$ \\ \{mperisa@fpz.hr' ${ }^{1}$, rsente@fpz.hr, icvitic@fpz.hr ${ }^{3}$, kolarovszki@gs1sk.org ${ }^{4}$ \} \\ University of Zagreb, Faculty of Transport and Traffic Sciences, Vukelićeva 4, Zagreb, Croatia ${ }^{123}$ \\ GS1 Slovakia, Nanterska 23,010 08 Žilina, Slovakia ${ }^{4}$
}

\begin{abstract}
The development of innovative information and communication technologies (ICT) and their implementation can contribute to greater efficiency of all logistic process elements. Industry 4.0 concept is focused on the implementation of ICT in logistic processes. Specific elements (warehouse, human, information) can be implemented in smart environment for efficient conduction of logistic processes. By defining workers requirements, analysis of ICT (sensors, RFID, NFC, Zigbee, IWN) and analysis of current ICT solutions (applications and devices), conceptual informing system architecture was proposed. The proposed architecture is based on IoT concept whose elements can provide object identification (packages, pallets, products) processes, automatization and data processing and storage. The concept uses Cloud Computing, IoT and specific sensor technologies depending on the simulation scenarios for the purpose of data collection, processing and storage. Security threats are shown as well as protection methods suggestions.
\end{abstract}

Keywords: Industrial Wireless Network, Smart Warehouse, Identification technology

\section{Introduction and previous research}

Industry 4.0 concept is focused on the implementation of ICT in business, development and manufacturing processes. It refers on the expansion of digital technologies in the fields of logistics and industry, especially sensor technologies in IoT environment for real-time data collection and processing [1]. Market requirements and development of innovative technologies changes the ways of conducting business processes of manufacturing organizations and creating smart factories and warehouses. Currently available research highlights the importance of IoT concept in the field of data collection and real-time information delivery [2]. According to Gartner, by 2020 there will be 20.4 billion of IoT devices worldwide [3]. Smart warehouses use RFID, barcode, Bluetooth, Wi-Fi and video surveillance to obtain insight on warehousing the products/pallets, their identification, location and tracking input and output products/pallets [4]. of sensor technology development, type and quantity of collected data is significantly increasing [5]. Warehouse management is one of the key elements in logistic processes and Smart Warehouse Management System (WMS) has different functionalities, depending on the warehouse functionalities. One of the most important segments of the system process for warehouse management requirements is to reduce the time that packages/pallets/products spend in the warehouse [6]. From the point of product users/customers, they need to be informed about the product status and its location in warehouse in real-time which affects on the ways that the products are moved and stored in warehouse [7], [8]. Since the central warehouse connects 
production and distribution sides, efficient warehouse operations need to be ensured. Current researches point out that the order picking process is one of the most expensive in warehouses, i.e. it makes up to $50-70 \%$ of total operating costs and $70 \%$ of order preparation time [9], [10]. For this reason, there is an increasing use of ICT within warehouses. It reduces operating costs, increases human labour efficiency and reduces operating activities time [11], [12], [13], [14]. AIDC (Automatic Identification and Data Capture) technologies, barcode, QR code and NFC (Near Field Communication) technology are used in warehouses for identification of warehouse entities [13], [15], [16]. Advantages of using NFC technology is the possibility to use it on mobile phone as a reader of NFC tags. Barcode can provide fast and reliable data delivery which ensures products/pallets/packages tracking and increases the quality of service to end users [15]. RTLS technology has a large application in logistic systems. It can provide efficiency of operating activities in warehouses and human labour [15], [17]. The aim of this research is to propose the design of conceptual informing system architecture in smart warehouse by using optimal ICT. The propose of this research is to optimize the work of logistic processes and WMS in smart warehouse environment.

\section{Analysis of warehouse processes and worker tasks}

The development and planning of warehouse space and solutions for production are based on changing patterns of market demands. For this reason, it is necessary to use quality designed WMS with the purpose to achieve high productivity and work automatization of dividing work activities inside warehouse. This reduces time of workers inactivity and provides needed information for further work tasks. Providing better flow of entities through warehouse space, planning the development of all processes inside organization (Enterprise Resource Planning, ERP), conducting warehouse control (WCS) and controlling equipment and devices inside warehouses (by using sensor technologies). Each order is divided into several tasks to achieve better efficiency of each process. WCS roles are focused on performing tasks given by WMS and controlling and optimization of subsystems such as system for storing and finding pallets. Warehouse is a part of distribution centre and is needed to ensure the fulfilment of all warehouse processes to achieve efficient work. Processes that are being performed inside warehouses are: goods admission, slotting, internal warehousing, ordering, accumulation and sorting, packaging, cross docking, sending and shipping of product entities. Supplier stores product entity in warehouse and each information about their condition and internal or external movement should be available in real-time. Figure 1. shows process of goods entering warehouse and their storing through 4 levels. Level 0 represents the area of goods arrival and their offloading from transportation vehicle. Level 1 represents the process of goods identification inside warehouse area, checking (type of goods to determine place for storage) and routing to slotting area. Location and goods storing is represented in Level 2 where the specific location for storing is defined and scanned as well as goods scanning. By checking scanned goods and location, data is being recorded in database. In case of incorrect data, the processes on Level 3 are being repeated. Identification of goods that is presented on Figure 1. is based on ICT described in research [18]. Tasks of workers that are stakeholders of storing and dispatching goods of warehouse processes are defined in researches [19], [20]. It is noted that there is a large time consumption on the processes for collecting, preparing, storing and delivery of goods inside warehouses. By using IoT and Industry 4.0 concept, it is possible to contribute to greater efficiency of workers and processes that are conducted inside warehouse [21]. 


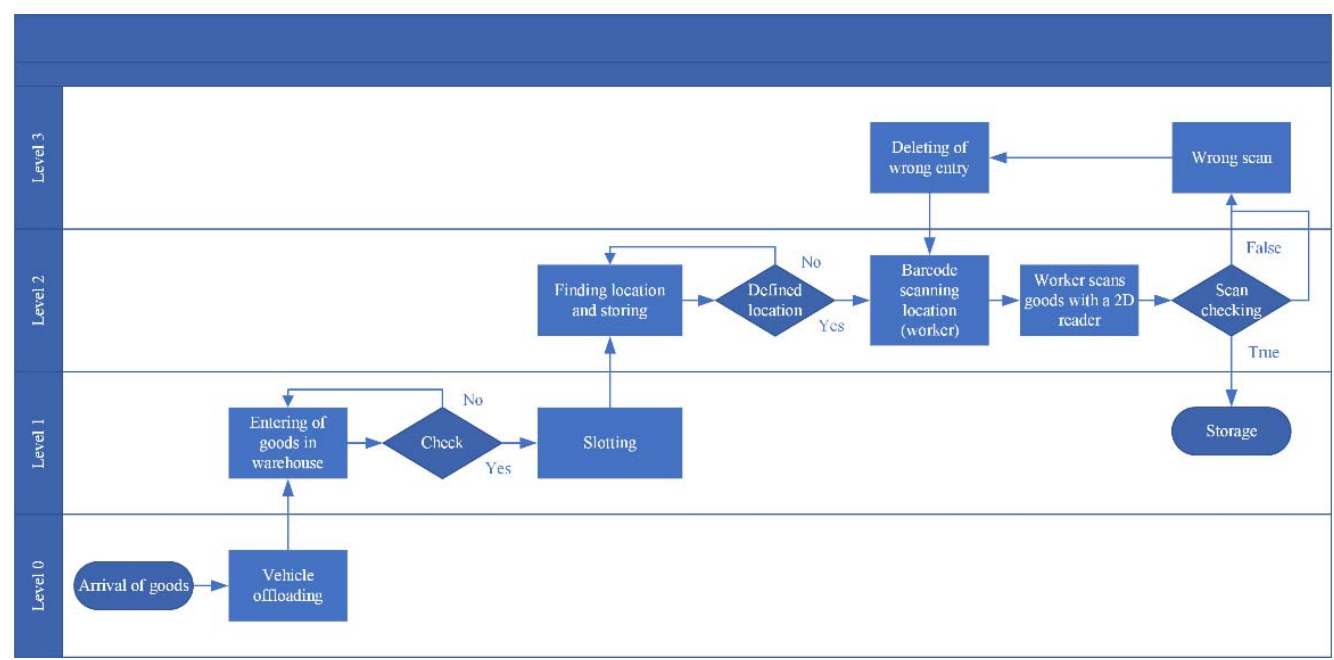

Fig 1. Process of accepting and storing goods in warehouse.

Tasks of warehouse workers according to the above-mentioned research are divided as: arrival of goods in warehouse (receiving goods, sorting, slotting to storage location, location scanning and storing) and outbound of goods to destination (receiving demands, finding goods, scanning, packing, shipping). When performing tasks, worker uses information and communication (IC) equipment such as RFID reader and related application. Disadvantage of using RFID technologies is damaged RFID tags which occur during the packing or transporting goods. Determining the location of the goods and their storing is part of the process that also requires certain time of a worker. Obtaining effective spent time on processes inside warehouse is possible to track by using WMS and optimal AIDC technology. By integrating WMS and optimal ICT, it is possible to track information inside warehouses (temperature, humidity, fire detection). Wireless networks with their technical characteristics, reasonable pricing, implementation flexibility and security features have advantages over other communication technologies and are optimal for smart warehouse areas [22].

\section{Wireless networks and Cloud Computing in Industry 4.0 concept characteristics}

The purpose of using WN (Wireless Networks) in Industry 4.0 concept is the integration of all relevant data and information obtained from the environment of the system end user. As for Industry 4.0 concept, it is recommended to use IWN (Industrial Wireless Networks) in the working processes of smart warehouses. Main differences between IWN and classic WN are [23]: latency (it refers to real-time information delivery. When working in such environment, the aspect of energy savings is important. Classic working application and devices in WSN environment have more energy consumptions when delivering real-time information); mobility (IWN network has more flexible and mobile devices in Industry 4.0 concept. It can include more mobile nodes which are important for using automated mobile entities and devices in network); environment (difference between IWN and WSN is in operative environment. This refers to work in warehouses and facilities where there are more humidity, different temperatures, dust, 
light, vibrations and other impacts. Signal network interference is possible because of different working machines and other networks. Industrial environment has impact on radio channel which is a disadvantage of WSN, while IWN needs additional working guidelines for ensuring greater reliability and communication with all devices and sensors); capacity (nodes of IWN require more capacity for storing and data processing. Energy consumption is more efficient regarding to classic WSN). IWN communication system can be divided into 4 components: smart entities, nodes, network components and mobile devices and providers. IWN nodes, smart entities (workers, AGV, machines, sensors) with wireless routers can be considered as wireless nodes. IWN access point nodes and gateway create connection to other networks such as mobile, wired, internet and other public networks (Figure 2).

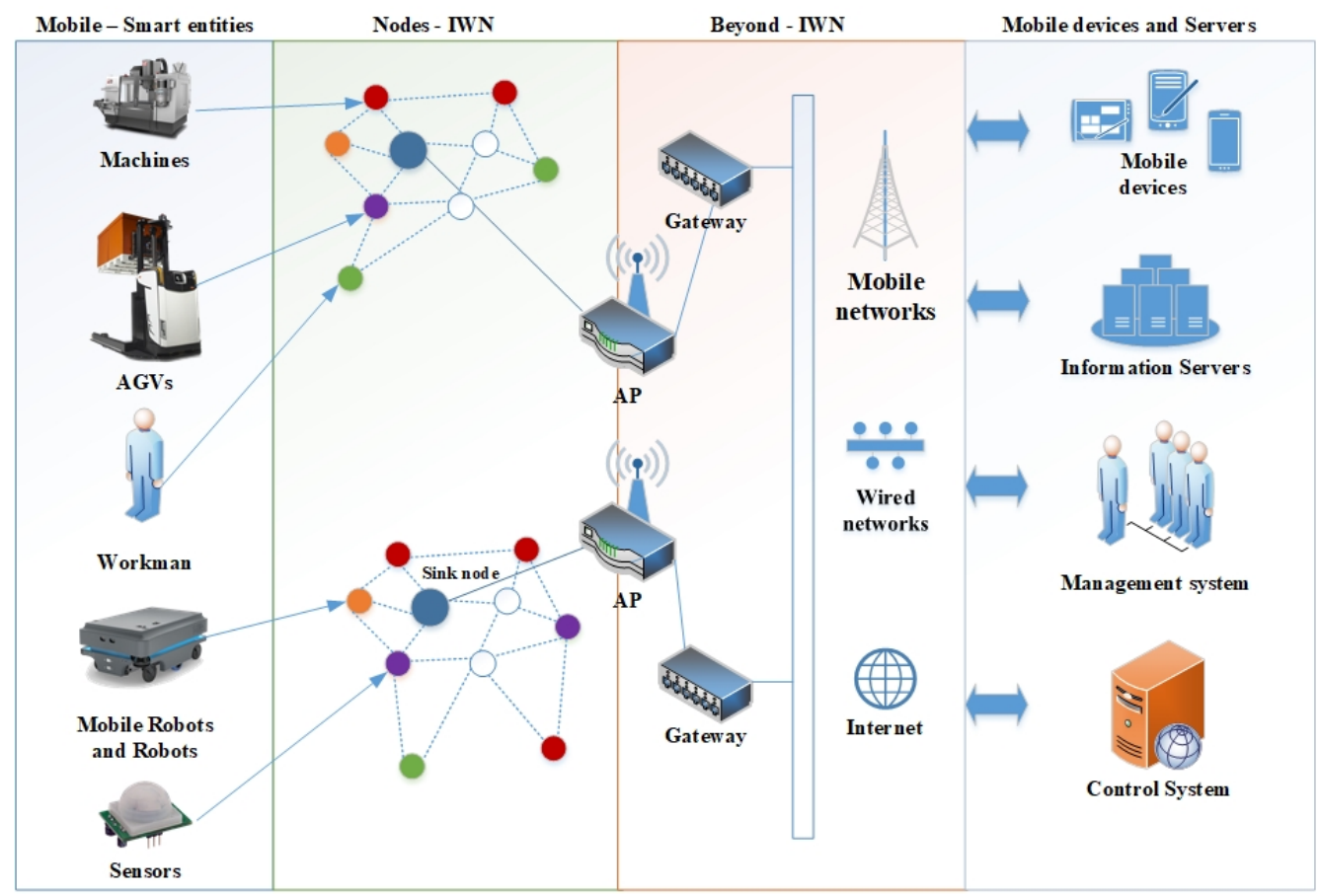

Fig 2. Schema representing IWN communication network, [25].

According to Gartner, by 2020, there will be 200 [ZB] of generated data in IoT environment and to provide real-time information, there will be a demand for information with minimal latency [24]. It is possible to use CC (Cloud Computing) and FC (Fog Computing) that is positioned on the edge of $\mathrm{CC}$ network with the purpose to offload the $\mathrm{CC}$ work. Primary usage of IWN in Industry 4.0 is in smart factories and warehouses. Communication protocols which can meet the demands of QoS elements (real-time, reliability, durability, security and privacy criteria) in such systems are: Zigbee, RFID, Wi-Fi, Bluetooth, NFC and other. This communication technologies with their characteristics can ensure collecting, processing, transferring and delivering of data in Industry 4.0 concept. Information can include data about factory, service, manufacturing and users. For this reason, it is necessary to satisfy levels of QoS and OoD (Quality-of-Data) with the aim of real-time information deliver. Implementation of 
sensor technologies inside warehouse area will affect on generating significant amount of data traffic. Wireless communication networks have larger application in Industry 4.0 concept regarding wired networks, especially because of the possible development of M2M (Machine to Machine) and mobile devices.

\section{Possibilities of implementation innovative smart wearable device in Industry 4.0}

According to previous researches, the main problem in warehouses is time spent on basic operating systems (picking, shipping, receiving, storing). Solutions based on IoT and web technologies showed the foundation for designing smart warehouses [25]. Such warehouses are efficiently organized but the disadvantage is the lack of significant number of sensors in warehouse environment. This reduces time of system response when sending demands for specific information.

\subsection{Proposition of conceptual informing system architecture}

This research proposes the possibility of using smart wearable wristband equipped with appropriate sensor technologies for efficient use of workers time in smart warehouses. By using IoT and web technologies it is possible to integrate all relevant data of logistic processes in one WMS. Proposed conceptual architecture shown on Figure 3 is based on characteristics of IWN.

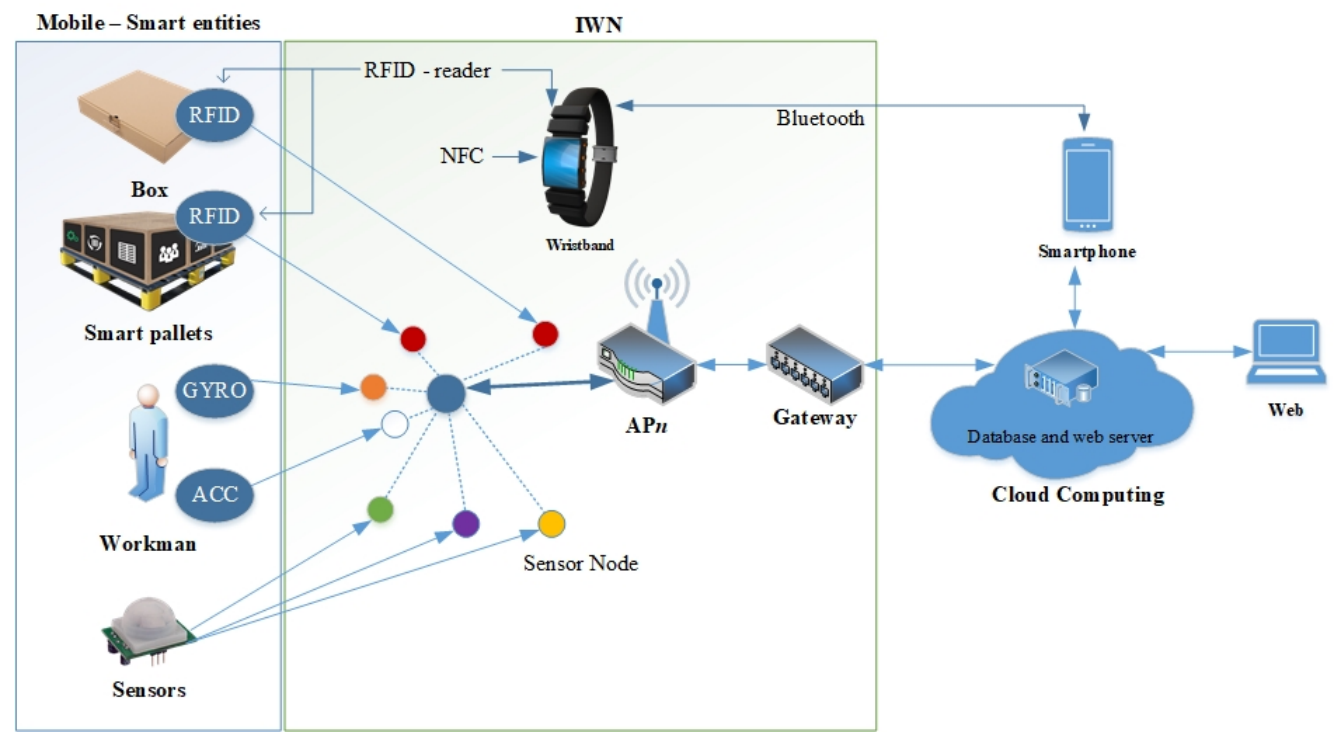

Fig. 3. Conceptual architecture of informing system for smart warehouse workers.

Network nodes should fulfil conditions of complex functionalities for processing and data storing with the purpose of smart forwarding of data for creating end information. These nodes require stronger modules such as processors, memory RF (Radio Frequency receivers), power 
suppliers and mechanical components. Each node can contain special roles that are defined according to the system requirements and workers of smart warehouse.

All collected information is stored in CC environment and this module can be integrated through WMS by using web applications. Smart warehouse is equipped with various sensors such as: temperature, humidity, fire detection, light, movement. Each of network nodes collects data that are forwarded to $\mathrm{CC}$ according to previously defined parameters. Process of identification of goods entering smart warehouse is done by RFID system which is implemented on the entry doors of smart warehouse. That information is send to CC environment and WMS. Contribution of proposed system is in using smart wristband by worker in smart warehouse instead of RFID reader. By using smart wristband user receives all relevant information that is collected from the smart warehouse environment and it has ability to read barcode information from products and pallets. User obtains information that are needed to determine the location of specific pallets of products. Smart wristband is also equipped with sensors for determining and tracking movement of worker to specific product. NFC technology on smart wristband gives the worker the possibility to identify his working time in smart warehouse and it provides other relevant information about worker.

\subsection{Working simulation of smart wristband}

Arduino platform is used for conducting simulation of architecture in IoT environment. This included sensors for measuring temperature, humidity, fire detection, light, NFC and RFID identification, accelerometer and gyroscope. The simulation is divided into two scenarios and two Arduino devices were used (Figure 4.).

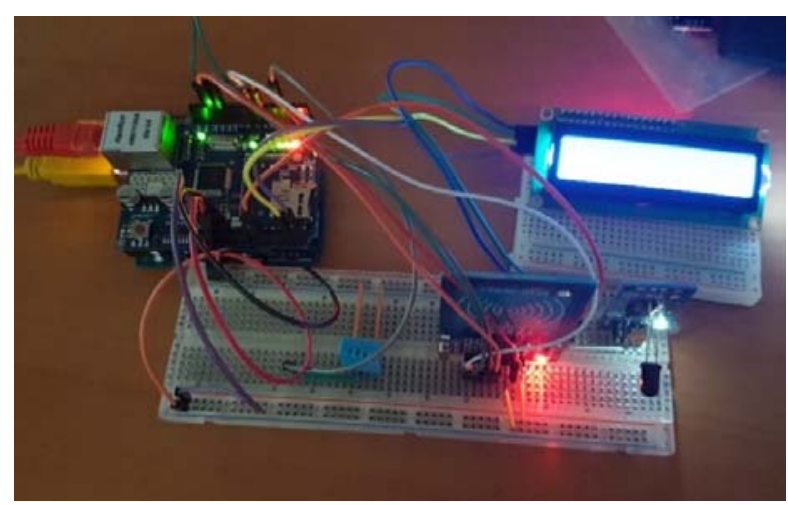

Fig. 4. Arduino and included sensors.

The first scenarios use sensors: DHT11 (humidity and temperature), RC522 (RFID), LM393 (fire detection) and LDR for light detection. The purpose of these sensors is to collect data from smart warehouse environment. RFID sensor simulates the work of antenna for identification of goods which enters smart warehouse environment. All collected information is forwarded to tracking system by using ThingSpeak web application which is shown on Figure 5. All changes are stored in database where there was 76.213 of input data. 

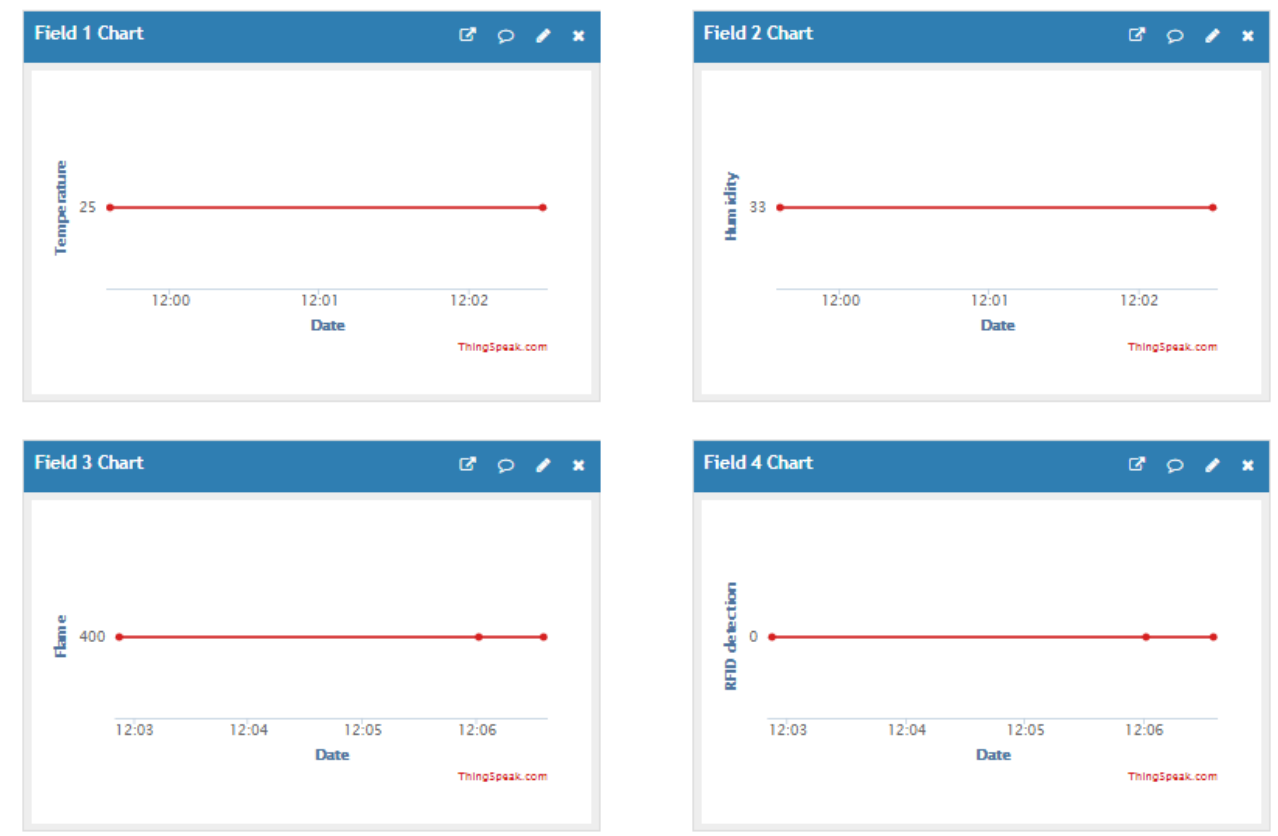

Fig. 5. Data collecting and visual representation in ThingSpeak application.

Second scenario simulates the work of smart wristband used by worker in smart warehouse. Sensors used for simulation are: PN532 (NFC and RFID) and MPU365 (accelerometer and gyroscope).

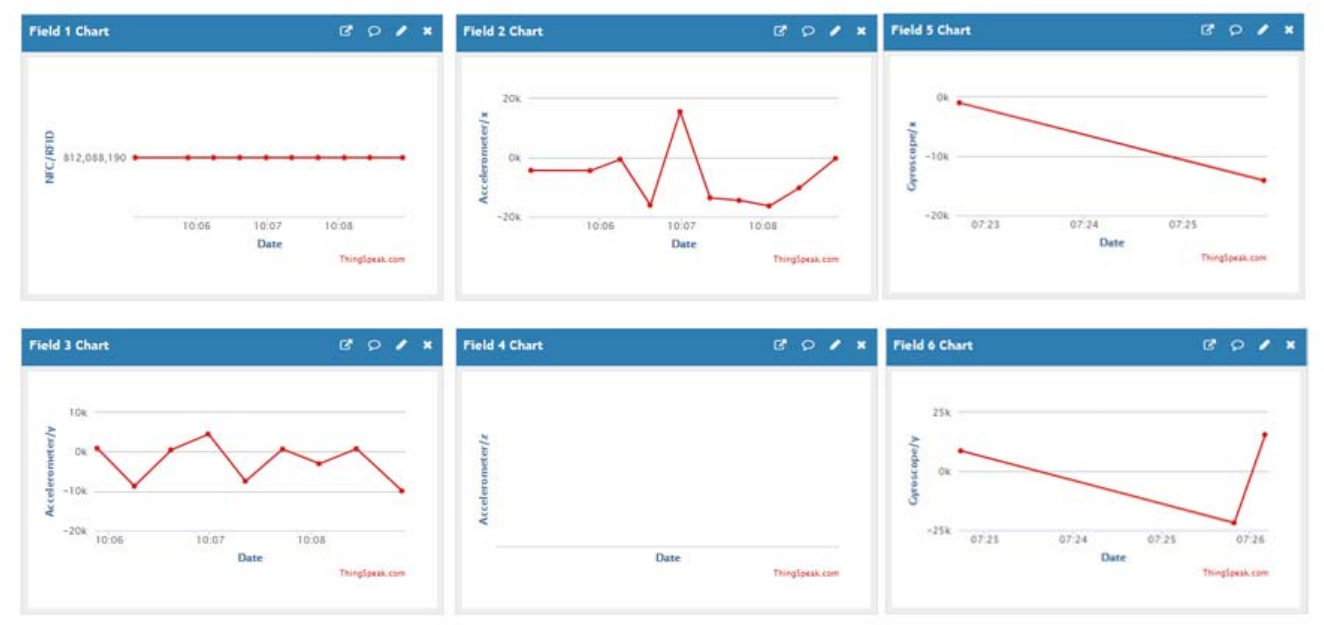

Fig. 6. Simulation of collecting data from smart wristband.

Platform for collecting and forwarding data to ThingSpeak environment is Arduino ethernet shield W5100. NFC module is used for worker identification, while RFID has the purpose to 
read RFID tags on products and pallets while accelerometer and gyroscope determine location of worker movement. Collecting data by simulating the work of smart wristband shows the data that are stored in simulated CC environment ThingSpeak is shown on Figure 6. The possibilities of working of smart wristband is shown in UML diagram on Figure 7.

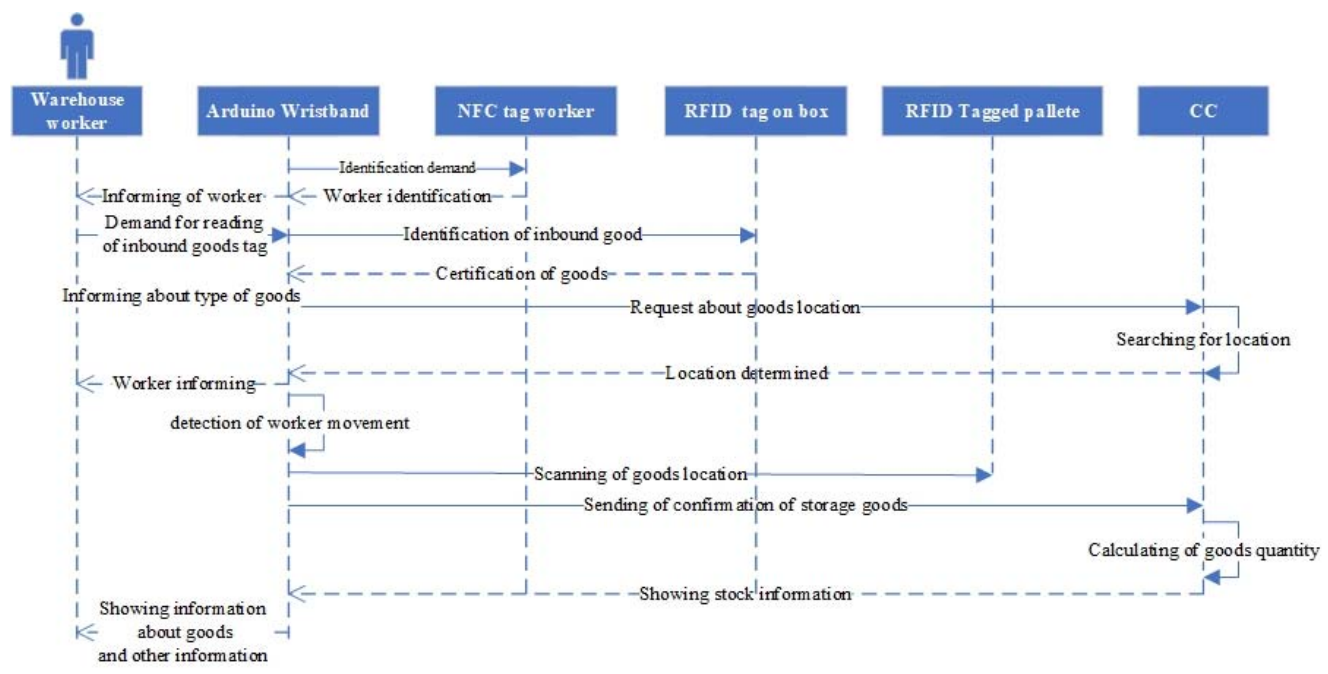

Fig. 7. Smart wristband overview by UML diagram.

Simulation of smart wristband shows the usage of sensor technologies based on conceptual architecture in IoT environment. In simulation environment, smart wristband had the purpose to identify users, read RFID tags and determine location and movement of user by using accelerometer and gyroscope.

\section{Cyber security challenges in Industry 4.0}

Industry 4.0 concept and technology that are used in it have security vulnerabilities as other organization systems. According to that, it is necessary to control internal and external threats as well as other shapes of business systems regardless their size. Smart logistic systems are interconnected with other numerous IC systems. This makes them as complex systems which results in variety of security threats [26]. IoT devices in Industry 4.0 concept are implemented for the purpose to increase the operative efficiency od logistic systems and processes. Security needs to be based on the control and data protection, identity and services in whole supply chain to avoid security incidents and threads [27]. The most common threads that need the most attention and try to avoid their influence are [26]: Cooperative cyber spying - higher risk of successful development of this threat goes from numerous smart and interconnected business processes. DoS (Denial of service) - since Industry 4.0 is based in mutual communication, DoS represents one of the key threats. This kind of threats have the potential to cause material damage (it requires sensor replacement, providers and other ICT equipment), but also to do material or operative damage (denial of service, processes and complex protocols that are needed for operative work). DoS is the threat that is hard or can not be anticipated and controlled. Supply 
chain and extended systems - one of the most important characteristics of Industry 4.0 concept is connectivity with organization environment to create efficient supply chain. However, supply chains have security vulnerabilities that can be exploited unauthorized. Vulnerability on identity theft and credentials (phishing attacks) is an example of vulnerability on supplier side which can cause massive leaking of confidential data. Industry 4.0 systems are designed to work in isolated environment. Their exposure to the public communication network exposes them to attach whose sophistication is on a stedy rise. The successfully implemented attack on the Industry 4.0 based system has the potential to cause incidents comparable to the largest, currently recorded, industrial incidents. Therefore, Industry 4.0 organizations need to establish reliable systems on a lever that is beyond of numerous traditional ICT systems. Establishing trustworthy systems needs to be based on five key system characteristics: security, safety, reliability, resilience and privacy [28].

\section{Conclusion}

Increasing application of contemporary ICT and services can contribute to efficient work of all logistic and industrial processes. Industry 4.0 as a new paradigm, with its broad application of functionalities and services should be the foundation for providing more efficient and productive industry and logistic world. This research identifies problems in logistic processes regarding time spend on warehouse processes. Time that worker loses when defining location for storing goods, identification of goods, its packaging and distribution is possible to minimise by using innovative services. By proposing conceptual architecture and simulation of its work in laboratory environments it is possible to improve WMS by smart wristband module and appropriate sensor technology. The role of smart wristbend and sensors in smart warehouse is in better and efficient informing of all relevant stakeholders of logistic chain. IWN and CC are the basis of the conceptual architecture and have the possibility to integrate all data with the purpose to deliver real-time information with minimum latency to end users.

\section{References}

[1] R. Strange and A. Zucchella, "Industry 4.0, global value chains and international business," Multinatl. Bus. Rev., vol. 25, no. 3, pp. 174-184, 2017.

[2] F. Shrouf, J. Ordieres, and G. Miragliotta, "Smart factories in Industry 4.0: A review of the concept and of energy management approached in production based on the Internet of Things paradigm," in 2014 IEEE International Conference on Industrial Engineering and Engineering Management, 2014, vol. 2015-Janua, pp. 697-701.

[3] Gartner, "Gartner Says 8.4 Billion Connected 'Things' Will Be in Use in 2017, Up 31 Percent From 2016," 2017.

[4] L. Juntao, "Research on Internet of Things Technology Application Status in the Warehouse Operation,” Int. J. Sci. Technol. Soc., vol. 4, no. 4, p. 63, 2016.

[5] J. Lee, H.-A. Kao, and S. Yang, "Service Innovation and Smart Analytics for Industry 4.0 and Big Data Environment," Procedia CIRP, vol. 16, pp. 3-8, 2014.

[6] G. Richards, Warehouse Management: A Complete Guide to Improving Efficiency and Minimizing Costs in the Modern Warehouse. 2017.

[7] A. Rosenfeld, O. Maksimov, S. Kraus, and N. Agmon, "Human-Multi-Robot Team Collaboration for Efficient Warehouse Operation."

[8] F. De Felice, A. Petrillo, and F. Zomparelli, "Design and control of logistic process in an Italian Company: Opportunities and Challenges based on Industry 4.0 principles," pp. 31-35. 
[9] T. C. Poon, K. L. Choy, H. K. H. Chow, H. C. W. Lau, F. T. S. Chan, and K. C. Ho, "A RFID case-based logistics resource management system for managing order-picking operations in warehouses," Expert Syst. Appl., vol. 36, no. 4, pp. 8277-8301, May 2009.

[10] S. Quader and K. K. Castillo-Villar, "Design of an enhanced multi-aisle order-picking system considering storage assignments and routing heuristics," Robot. Comput. Integr. Manuf., vol. 50, pp. 13-29, Apr. 2018.

[11] K. L. Choy, G. T. S. Ho, and C. K. H. Lee, "A RFID-based storage assignment system for enhancing the efficiency of order picking," J. Intell. Manuf., vol. 28, no. 1, pp. 111-129, Jan. 2017.

[12] L. Feng, "Intelligent logistics and distribution system based on Internet of Things," in 2016 IEEE Advanced Information Management, Communicates, Electronic and Automation Control Conference (IMCEC), 2016, no. Iv, pp. 228-231.

[13] F. Liu, Z. Qin, Y. Zhang, and X. Hou, "The Application of NFC Verification System in Warehouse Management System," in 6th International Conference on Information Engineering for Mechanics and Materials (ICIMM 2016), 2016, no. Icimm, pp. 710-716.

[14] P. Thanapal, J. Prabhu, and M. Jakhar, "A survey on barcode RFID and NFC," IOP Conf. Ser. Mater. Sci. Eng., vol. 263, no. 4, p. 042049, Nov. 2017.

[15] T. E. Erkan and G. F. Can, "Selecting the best warehouse data collecting system by using AHP and FAHP methods," Teh. Vjesn., vol. 21, no. 1, pp. 87-93, 2014.

[16] L. Chunli and L. Donghui, "Application and development of RFID technique," in 2012 2nd International Conference on Consumer Electronics, Communications and Networks (CECNet), 2012, pp. 900-903.

[17] D. Bin, C. Li, C. Dianlong, and Y. Haitao, "Application of RTLS in warehouse management based on RFID and Wi-Fi," in 2008 International Conference on Wireless Communications, Networking and Mobile Computing, WiCOM 2008, 2008, no. 070416277, pp. 1-5.

[18] D. Peraković, M. Periša, and R. E. Sente, "Information and Communication Technologies Within Industry 4.0 Concept," in Lecture Notes in Mechanical Engineering, 2019, pp. 127-134.

[19] H. E. Frazelle, World-Class Warehousing and Material Handling, 2nd ed. McGraw-Hill Education, 2016.

[20] R. Manzini, R. Accorsi, L. Pattitoni, and A. Regattieri, "A Supporting Decisions Platform for the Design and Optimization of a Storage Industrial System," in Efficient Decision Support Systems Practice and Challenges in Multidisciplinary Domains, vol. 2, InTech, 2011, p. 64.

[21] C. K. M. Lee, Y. Lv, K. K. H. Ng, W. Ho, and K. L. Choy, "Design and application of Internet of things-based warehouse management system for smart logistics," Int. J. Prod. Res., vol. 56, no. 8, pp. 2753-2768, Apr. 2018.

[22] R. B. M. De Koster, A. L. Johnson, and D. Roy, "Warehouse design and management."

[23] X. Li, D. Li, J. Wan, A. V. Vasilakos, C.-F. Lai, and S. Wang, "A review of industrial wireless networks in the context of Industry 4.0," Wirel. Networks, vol. 23, no. 1, pp. 23-41, Jan. 2017.

[24] Forbes, "Gartner Predicts Three Big Data Trends for Business Intelligence," 2015. [Online]. Available: https://www.forbes.com/sites/gartnergroup/2015/02/12/gartner-predicts-three-big-datatrends-for-business-intelligence/\#75bf60ac6de4.

[25] S. Jabbar, M. Khan, B. N. Silva, and K. Han, "A REST-based industrial web of things' framework for smart warehousing," J. Supercomput., Dec. 2016.

[26] T. Pereira, L. Barreto, and A. Amaral, "Network and information security challenges within Industry 4.0 paradigm," Procedia Manuf., vol. 13, pp. 1253-1260, 2017.

[27] Symantec, "Smarter Security for Manufacturing in the Industry 4 . 0 Era," pp. 1-12, 2016.

[28] S. Schrecker et al., "Industrial Internet of Things Volume G4: Security Framework," Ind. Internet Consort., pp. 1-173, 2016. 